\title{
Influence of aggregation and measurement scale on ranking a compromise alternative in AHP
}

\author{
A Ishizaka ${ }^{1 *}, \mathrm{D}$ Balkenborg ${ }^{2}$ and T Kaplan ${ }^{2}$ \\ ${ }^{1}$ University of Portsmouth, Portsmouth Business School, Portsmouth, UK; and ${ }^{2}$ Department of Economics, \\ University of Exeter Business School, Rennes Drive, UK
}

Analytic Hierarchy Process (AHP) is one of the most popular multi-attribute decision aid methods. However, within AHP, there are several competing preference measurement scales and aggregation techniques. In this paper, we compare these possibilities using a decision problem with an inherent trade-off between two criteria. A decision-maker has to choose among three alternatives: two extremes and one compromise. Six different measurement scales described previously in the literature and the new proposed logarithmic scale are considered for applying the additive and the multiplicative aggregation techniques. The results are compared with the standard consumer choice theory. We find that with the geometric and power scales a compromise is never selected when aggregation is additive and rarely when aggregation is multiplicative, while the logarithmic scale used with the multiplicative aggregation most often selects the compromise that is desirable by consumer choice theory.

Journal of the Operational Research Society advance online publication, 17 March 2010 doi:10.1057/jors.2010.23

Keywords: decision analysis; multiple criteria analysis; utility theory; additive AHP; multiplicative AHP; logarithmic scale

\section{Introduction}

Analytic Hierarchy Process (AHP) (Saaty, 1977, 1980) is a multi-criteria decision method applied to a wide variety of situations with impressive results. The Journal of the Operational Research Society has recently reported several successful applications in different areas: Information Systems (Ahn and Choi, 2008), Supply Chain Management (Akarte et al, 2001; Sha and Che, 2006; Yeo et al, 2009), Public services (Fukuyama and Weber, 2002; Mingers et al, 2009), Health (Lee and Kwak, 1999; Li et al, 2009), Strategy (Leung et al, 2006), E-learning (Tavana, 2006), Defence (Wheeler, 2006) and Manufacturing (Bañuelas and Antony, 2007). There are also several surveys on the success of AHP (Zahedi, 1986; Golden et al, 1989; Vargas, 1990; Forman and Gass, 2001; Vaidya and Kumar, 2006; Ho, 2008; Liberatore and Nydick, 2008).

Although AHP is widely used, the literature has proposed different variants for the measurement scale and the aggregation of the local priorities, which may lead to different final results. This may be an advantage as each of the different ways to model the problem may be suited for a different application. However, unaware users may apply

\footnotetext{
* Correspondence: A Ishizaka, University of Portsmouth, Portsmouth Business School, Richmond Building, Portland Street, Portsmouth, PO1 3DE, Hampshire, UK.
}

AHP incorrectly, which may result in a suboptimal recommendation.

In this paper, we describe a decision problem with an inherent trade-off between two criteria. For instance, a job may require two unrelated skills and workers tend not to be adept at both. We compare the additive AHP and its variant the multiplicative AHP (MAHP) with the utility theory to evaluate the choice among three alternatives: two extremes and one compromise. The utility theory has a normative approach and AHP a descriptive or a practical orientation (Winkler, 1990). In this paper, we aim to demonstrate that the aggregation method of local priorities and the measurement scale in AHP has a strong influence on the selection of the compromise and therefore on the degree of concordance with the utility theory.

\section{AHP}

\subsection{General description of the method}

At the heart of the AHP method are the comparison matrices $\mathbf{A}=\left(a_{i, j}\right), i, j=1, \ldots, n$, where $a_{i, j}$ are pairwise comparisons from alternatives/criteria given by the decision-maker on a verbal scale of nine levels (Table 1). Local priorities $\mathbf{l}_{l}=l_{i}, i=$ $1, \ldots, n$ are then calculated from these comparison matrices. Finally, the local priorities are weighted with the criterion priority and aggregated to give the global priority $p_{i}$ of the alternatives. 
Table 1 The nine levels of the comparison scale, including the intermediate levels $\mathrm{B}, \mathrm{D}, \mathrm{F}$ and $\mathrm{H}$

\begin{tabular}{ll}
\hline Levels & Definitions \\
\hline $\mathrm{A}$ & Equal importance \\
$\mathrm{B}$ & Equal-weak importance \\
$\mathrm{C}$ & Weak importance \\
$\mathrm{D}$ & Weak-strong \\
$\mathrm{E}$ & Strong importance \\
$\mathrm{F}$ & Strong-very strong importance \\
$\mathrm{G}$ & Very strong importance \\
$\mathrm{H}$ & Very strong-absolute importance \\
$\mathrm{I}$ & Absolute importance \\
\hline
\end{tabular}

An AHP matrix is said perfectly consistent if for all comparison $a_{i, j}$ respect the following transitivity (1) and reciprocity (2) rules:

$$
a_{i, j}=a_{i, k} \cdot a_{k, j},
$$

where $i, j$ and $k$ are any alternatives of the matrix.

$$
a_{i, j}=\frac{1}{a_{j, i}} .
$$

However, AHP accepts some inconsistencies in the entries, which happens in practice. A consistency check must be applied. Saaty $(1977,1980)$ has proposed the consistency index $(\mathrm{CI})$ :

$$
\mathrm{CI}=\frac{\lambda_{\max }-n}{n-1},
$$

where $n$ is dimension of the matrix and $\lambda_{\max }$ is maximal eigenvalue.

The calculated priorities are plausible only for slightly inconsistent matrices: if the consistency ratio (CR) (4), ratio of $\mathrm{CI}$ and $\mathrm{RI}$ (the average $\mathrm{CI}$ of 500 randomly filled matrices), is less than $10 \%$.

$$
\mathrm{CR}=\frac{\mathrm{CI}}{\mathrm{RI}},
$$

where $\mathrm{CR}$ is consistency ratio and RI is random index (Table 2).

Saaty (1977) calculated the random indices as given in Table 2.

\subsection{Measurement scales}

One of AHP's strengths is the possibility to evaluate quantitative and also qualitative criteria and alternatives on the same preference scale, namely a verbal scale. The use of verbal responses is intuitively appealing, user friendly and more common in our everyday lives than numbers. It may also allow some ambiguity in non-trivial comparisons. To derive priorities, the verbal comparisons must be converted into numerical ones. In Saaty's AHP, the verbal statements are converted into integers from 1 to 9 . Theoretically there is no reason to be restricted to these numbers. Therefore, other scales have been proposed (Table 3). Harker and Vargas (1987) have evaluated a quadratic and a root square scale in only one simple example and argued in favour of Saaty's 1-9 scale. However, one example seems not enough to conclude the superiority of the 1-9 linear scale. The entered comparisons are not unique: they depend on the decision-maker. Lootsma (1989) argued that the geometric scale is preferable to the 1-9 linear scale. Salo and Hämäläinen (1997) point out that the integers from 1 to 9 yield local weights, which are unevenly dispersed, so that there is lack of sensitivity when comparing elements, which are preferentially close to each other. Based on this observation, they propose a balanced scale in which the local weights are evenly dispersed over the weight range [0.1, 0.9]. Earlier, Ma and Zheng (1991) have calculated an inverse linear scale, which also gives more uniformly distributed priorities than the 1-9 scale. For our study, we will also propose a logarithmic scale, which is smoother for high values. Figures 1 and 2 show the used scales in the study.

Among all the proposed scales, the linear scale with the integers 1-9 and their reciprocals has been used by far the most often in applications. Saaty (1980, 1991) advocates it as the best scale to represent weight ratios. Combined with cluster techniques, the upper limit scale problem can be avoided (Saaty, 1991; Ishizaka, 2004a, 2004b). However, the cited examples deal with objective measurable alternatives like the areas of figures, whereas AHP treats mainly decision processes on subjective issues. We understand the difficulty of verifying the effectiveness of scales through subjective issues. Salo and Hämäläinen (1997) demonstrate the superiority of the balanced scale when comparing two elements. The choice of the 'best' scale is a very heated debate. Some scientists agree that the choice depends on the person and the decision problem (Harker and Vargas, 1987; Pöyhönen et al, 1997). Our paper aims to shed some light on the choice of the appropriate scale and aggregation technique (see Section 2.3). We will run a complete enumeration with the different type of scales for the additive and MAHP and then draw a parallel with the consumer choice theory.

\subsection{Aggregation}

The calculation of global priorities $\left(p_{i}\right)$ results from the aggregation of the local priorities $\left(l_{i j}\right)$ and the weight $\left(w_{j}\right)$ of the criterion $j$. Saaty $(1977,1980)$ has proposed an additive approach (5). This method has been attacked by Belton and Gear (1983) and Holder (1990, 1991), because the introduction of a copy of an alternative or a near copy (Dyer, 1990) would change the ranking. This phenomenon is called in the literature 'rank reversal'. Saaty (1990) and Harker and Vargas (1990) have defended the method saying that it is legitimate that the introduction of new information (even a copy of the existing one) is able to change the ranking. 
Table 2 Random indices

\begin{tabular}{ccccccccc}
\hline$N$ & 3 & 4 & 5 & 6 & 7 & 8 & 9 & 10 \\
\hline RI & 0.58 & 0.9 & 1.12 & 1.24 & 1.32 & 1.41 & 1.45 & 1.49 \\
\hline
\end{tabular}

Table 3 Different scales for comparing two alternatives (for the comparison of $\mathrm{A}$ and $\mathrm{B}, c=1$ indicates $\mathrm{A} \approx \mathrm{B}$; $c>1$ indicates $\mathrm{A}>\mathrm{B}$; when $\mathrm{A}<\mathrm{B}$, the reciprocal values $1 / c$ are used)

\begin{tabular}{lll}
\hline Scale & Definition & Parameters \\
\hline Linear (Saaty, 1977) & $c=a \cdot x$ & $a>0 ; x=1,2, \ldots, 9$ \\
Power (Harker and Vargas, 1987) & $c=x^{a}$ & $a>1 ; x=1,2, \ldots, 9$ \\
Geometric (Lootsma, 1989) & $c=a^{x-1}$ & $a>1 ; x=1,2, \ldots, 9$ \\
Logarithmic & $c=\log _{a}(x+1)$ & $a>1 ; x=1,2, \ldots, 9$ \\
Root square (Harker and Vargas, 1987) & $c=\sqrt[a]{x}$ & $a>1 ; x=1,2, \ldots, 9$ \\
Inverse linear (Ma and Zheng, 1991) & $c=9 /(10-x)$ & $x=1,2, \ldots, 9$ \\
Balanced (Salo and Hämäläinen, 1997) & $c=w /(1-w)$ & $w=0.5,0.55,0.6, \ldots, 0.9$ \\
\hline
\end{tabular}

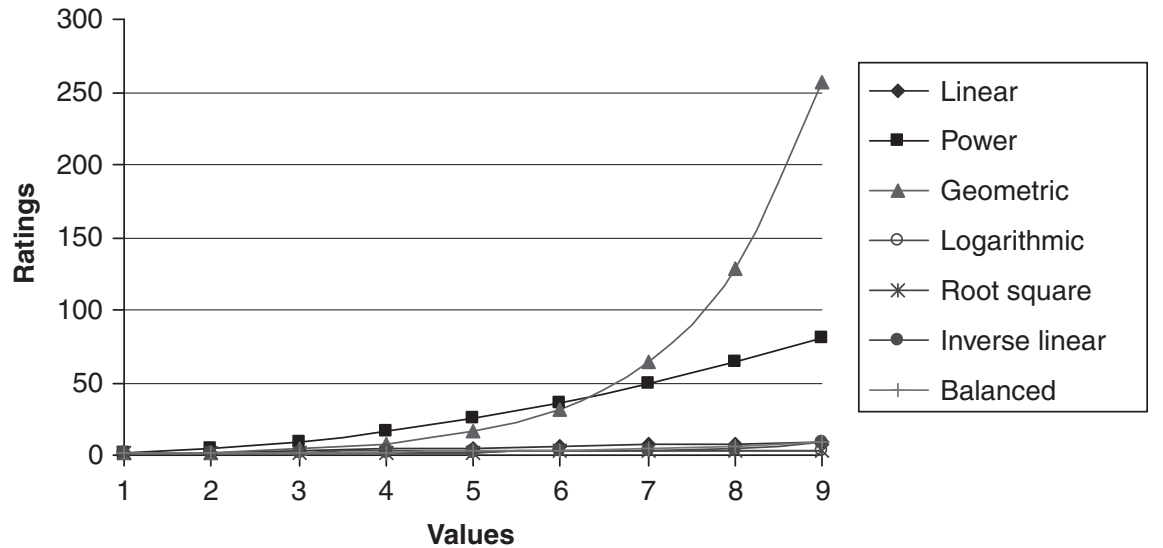

Figure 1 Graph of the judgement scales used in the study, $a=1$ for the linear scale and $a=2$ for all other scales.

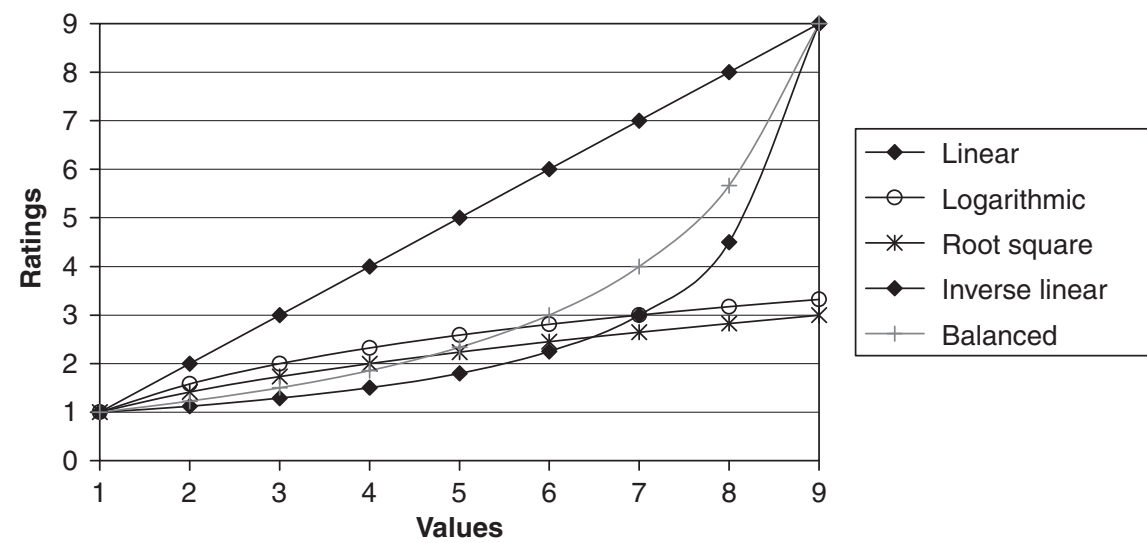

Figure 2 Graph of the judgement scales without the geometric and power scales, $a=1$ for the linear scale and $a=2$ for all other scale.

Barzilai and Golany (1994), Barzilai (1997) and Triantaphyllou (2001) argued that the rank reversal problem in the AHP is due to an erroneous use of the additive aggrega- tion method. Instead the multiplicative method (6) (Lootsma et al, 1990; Lootsma, 1993; Leskinen and Kangas, 2005) should be used. Contrary to the additive AHP, where the sum 
of the criteria weights is equal to the unity $\sum_{j} w_{j}=1$, the MAHP does not require this normalisation.

$$
\begin{gathered}
p_{i}=\sum_{j} w_{j} \cdot l_{i, j} \\
p_{i}=\prod_{j} l_{i, j}^{w_{j}},
\end{gathered}
$$

where $p_{i}$ is global priority of the alternative $i ; l_{i, j}$ is local priority of the alternative $i$; with respect to the criterion $j$ and $w_{j}$ is weight of the criterion $j$.

In response, Vargas (1997) gives an example in which the exact weight of objects can be retrieved only by an additive aggregation of the local comparisons. Due to its rank reversal preservation and its non-linear properties (Triantaphyllou and Baig, 2005), the MAHP seems to receive a growing attention. In particular Stam and Duarte Silva (2003) notice that the additive AHP tends to overweight extreme alternatives, which seems not to be the case for the MAHP. He suggests that further research should be done to confirm these observations. It is the aim of this paper.

\section{Theory of consumer choice}

\subsection{Description of the problem}

For our study, we choose a simple multi-criteria decision problem. This simple problem is not only easy to study, but it also captures the essence of the choice problem for which AHP and MAHP is used. Moreover, if AHP fails to handle adequately this simple problem, it is doubtful that it will be able to handle a more difficult one.

The problem is as follows. A company has to hire a new sales engineer. The position requires both engineering and sales skills. Three candidates with different profiles are available (see Table 4).

Which candidate will be selected? The consumer choice theory sets three main axioms about the preferences of the consumer:

Rationality: The consumer preferences are complete (no preferences are undefined) and consistent (satisfying Equations (1) and (2)). ${ }^{1}$

Monotonicity: The consumer prefers to hire a candidate who has more skill than less, where skill is being considered as a normal aptitude or attribute. For example, if two candidates have the same skill in sales but the first has more ability in engineering than the second one, the first candidate will be preferred. The hypothesis implies that the indifference curves have a negative slope like in Figure 3.

\footnotetext{
${ }^{1}$ AHP only partially requires this hypothesis.
}

Table 4 Candidates A, B, C with their respective knowledge

\begin{tabular}{lll}
\hline Candidates & Engineering skills & Sales skills \\
\hline $\mathrm{A}$ & High & Low \\
$\mathrm{B}$ & Medium & Medium \\
$\mathrm{C}$ & Low & High \\
\hline
\end{tabular}

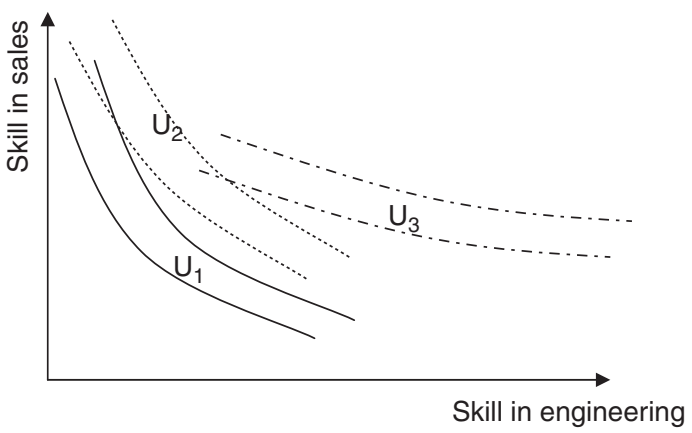

Figure 3 Three types of indifference curves.

Convexity: Simply, the consumer prefers a mix to the extremes. For instance, if a consumer is indifferent to either 10 apples or 10 oranges, then the consumer prefers 5 apples and 5 oranges to either of these options. The hypothesis is discussed in introductory economic textbooks as the 'law of diminishing marginal rates of substitution'. It implies that the indifference curves are upward bowed (all points on a line between two points on an indifference curve must be on a higher indifference curve) like in Figure 3.

Indifference curves connect all alternatives (represented by vectors of attributes) that leave the consumer indifferent. In Figure 3, the set of curves $U_{1}, U_{2}$ and $U_{3}$ have three different inclinations. They represent the utility of three different people. Curves $U_{1}$ are the indifference curves for a person having symmetric preferences between the importance of criteria skill in sales and skill in engineering for the position to fill. Curves $U_{2}$ correspond to a big importance in the criterion skill in engineering and curves $U_{3}$ indicate a preference for the skill in sales.

The employer will choose the candidate on the highest indifference curve. For example, in Figure 4, the candidate $B$ is preferred because he lies on a higher indifference curve than $\mathrm{A}$ and $\mathrm{C}$.

\subsection{Decision with the consumer choice theory}

We consider the problem of Table 4, where a decision-maker has to decide between three candidates $\mathrm{A}, \mathrm{B}$ and $\mathrm{C}$ for a position to fulfil. They have different skills in engineering and sales. Let $s_{I}^{\text {eng }}$ and $s_{I}^{\text {sales }}$ be the objectives measures of their engineering and sales skills for $I$, one of the three candidates. 


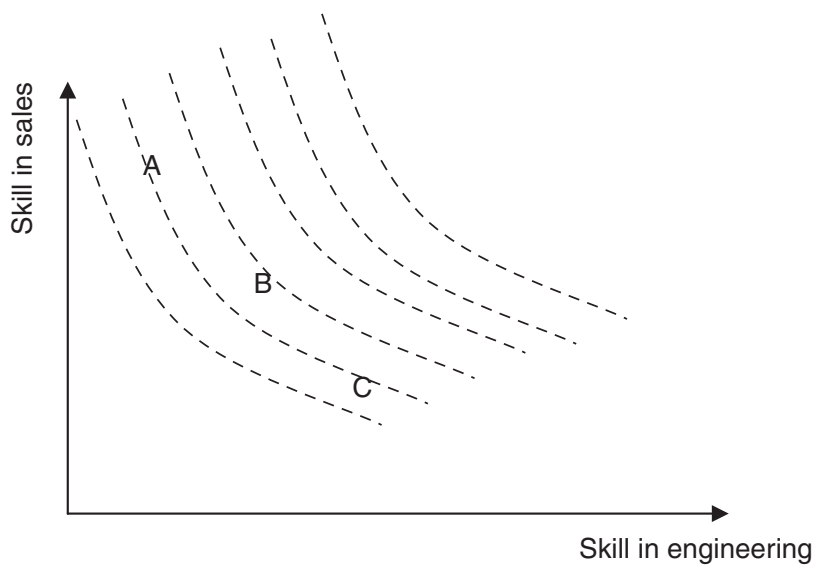

Figure 4 The candidate $\mathrm{B}$ is preferred because he lies on a higher utility curve of the employer.

From Table 4:

$$
\begin{aligned}
& s_{A}^{\text {eng }}>s_{B}^{\text {eng }}>s_{C}^{\text {eng }} \\
& s_{A}^{\text {sales }}<s_{B}^{\text {sales }}<s_{C}^{\text {sales }} .
\end{aligned}
$$

In addition we assume that the compromise alternative is symmetric with respect to both skill variables, so

$$
s_{B}^{\text {eng }}=s_{B}^{\text {sales }} .
$$

We assume the decision-maker to have a standard utility function $u\left(s_{I}^{\text {eng }}, s_{I}^{\text {sales }}\right)$, which satisfies the assumptions of Table 4 and depends only on the two engineering and sales skills. The candidate $I$ with the highest utility $u\left(s_{I}^{\text {eng }}, s_{I}^{\text {sales }}\right)$ will be preferred.

In order to use AHP, the decision-maker has to estimate the relative skill $c_{I, J}^{x}=s_{I}^{x} / s_{J}^{x}$ of candidate $I$ in comparison to candidate $J$ with respect to his ability in skill $x$. We are aware that the $c_{I, J}^{x}$ are subjective and potentially inaccurate estimates, which must be mapped into a measurement scale, for example the $1 / 9,1 / 8, \ldots 1 / 2,1,2, \ldots, 8,9$ Saaty scale. Hence, we use an inverse mapping that goes from the measurement scale into the ratio of skills. We denote this inverse mapping as $z(x)$ with the requirement that $z(x)>0, z^{\prime}(x)>0$ and $z(x)=1 / z(1 / x)$ (which implies $z(1)=1)$. For most of the analysis, we use the function $z(x)=x$.

The inequalities (7) and (8) for the absolute skill measures imply:

$$
\begin{aligned}
& c_{A, C}^{\text {eng }}>c_{B, C}^{\text {eng }}>1, c_{A, B}^{\text {eng }}>1 \\
& c_{A, C}^{\text {sales }}<c_{B, C}^{\text {sales }}<1, c_{A, B}^{\text {sales }}<1 .
\end{aligned}
$$

Since (1), the transitivity rule $c_{A, C}^{\text {eng }}=c_{A, B}^{\text {eng }} \cdot c_{B, C}^{\text {eng }}$, holds for known skills and since both factors in the product are larger than one, we obtain

$$
c_{A, C}^{\text {eng }}>\max \left\{c_{A, B}^{\text {eng }} ; c_{B, C}^{\text {eng }}\right\} .
$$

As the transitivity rule is too rigid in our inconsistent world, we will throughout impose the weak consistency requirement (12).

Identically for the criterion skill in sales, we can deduce the weak consistency requirement:

$$
c_{A, C}^{\text {sales }}<\min \left\{c_{A, B}^{\text {sales }} ; c_{B, C}^{\text {sales }}\right\} .
$$

For our study, we assume that the skill in engineering and in sales have the same utility. In AHP, this means that the criteria skill in sales and skill in engineering are of equal weight.

The comparison $c_{I J}^{x}$ between candidate $I$ and $J$ as regards to the criterion $x$ can take 17 values (Table 1). If we evaluate three alternatives with AHP, $17^{3}=4913$ different matrices are possible. This result must then be squared because we have two criteria. However, most of these matrices would be highly inconsistent and do not reflect the problem described in Table 4. To be consistent with our setup, we include the conditions (9), (10), (11), (12), (13) and we consider only acceptable inconsistent matrices $(\mathrm{CR}<0.1)$.

Moreover, the number of cases in which the compromise $\mathrm{B}$ is selected depends on the utility function. We now describe four special cases: the Cobb-Douglas utility function, the perfect complements, perfect substitutes and the geometric mean.

In accordance with standard consumer theory, we would expect that in most cases the consumer would prefer the compromise alternative $\mathrm{B}$.

\section{(a) Cobb-Douglas}

The Cobb-Douglas utility function is the most widely used utility function in applied and theoretical economics. Cobb-Douglas preferences have convex indifference curves and are represented by the utility function

$$
u\left(x_{1}, x_{2}\right)=x_{1}^{c} x_{2}^{d},
$$

where $c$ and $d$ are strictly positive numbers.

In our study, we assume that the skill in engineering and in sales have the same weight in the consumer's preferences, that is, $c=d$. We can also normalise $c=d=1$ without loss of generality.

With the Cobb-Douglas utility function, the compromise candidate $\mathrm{B}$ will be preferred by the decision-maker if:

$$
\left[s_{B}^{\text {eng }}\right]\left[s_{B}^{\text {sales }}\right] \succ \max \left[\left[s_{A}^{\text {eng }}\right]\left[s_{A}^{\text {sales }}\right] ;\left[s_{C}^{\text {eng }}\right]\left[s_{C}^{\text {sales }}\right]\right] .
$$

The condition (15) can be decomposed in two equations, one for each candidate:

$$
\begin{aligned}
& {\left[s_{B}^{\text {eng }}\right]\left[s_{B}^{\text {sales }}\right] \succ\left[s_{A}^{\text {eng }}\right]\left[s_{A}^{\text {sales }}\right] \text { and }} \\
& {\left[s_{B}^{\text {eng }}\right]\left[s_{B}^{\text {sales }}\right] \succ\left[s_{C}^{\text {eng }}\right]\left[s_{C}^{\text {sales }}\right]}
\end{aligned}
$$

and by grouping the same skills, we obtain:

$$
\left[\frac{s_{B}^{\text {sales }}}{s_{A}^{\text {sales }}}\right] \succ\left[\frac{s_{A}^{\text {eng }}}{s_{B}^{\text {eng }}}\right] \text { and }\left[\frac{s_{B}^{\text {eng }}}{s_{C}^{\text {eng }}}\right] \succ\left[\frac{s_{C}^{\text {sales }}}{s_{B}^{\text {sales }}}\right] \text {. }
$$




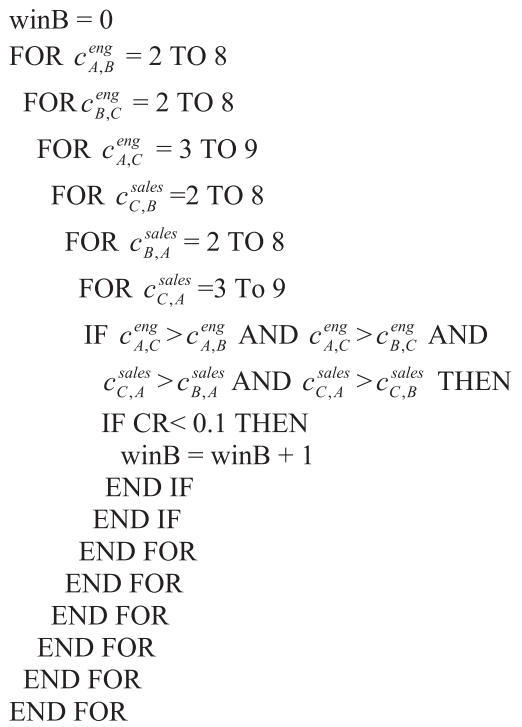

Figure 5 Pseudocode for the calculation of the maximum numbers of $\mathrm{B}$ wins.

For any particular inverse mapping $z\left(c_{12}\right)=s_{1} / s_{2}$ from measurement scales to ratio of skills these become:

$$
z\left(c_{B, A}^{\text {sales }}\right)>z\left(c_{A, B}^{\text {eng }}\right) \text { and } z\left(c_{B, C}^{\text {eng }}\right)>z\left(c_{C, B}^{\text {sales }}\right) .
$$

Since $z$ is positive and increasing, we have:

$$
c_{B, A}^{\text {sales }}>c_{A, B}^{\text {eng }} \text { and } c_{B, C}^{\text {eng }}>c_{C, B}^{\text {sales }} .
$$

These conditions are the same for any interpretation the user may have for the comparisons entered into AHP (represented by different $z$ functions). For the above, we do not need the symmetry assumption in (9). This is because the Cobb-Douglas utility function is the only utility function in which the preference can be expressed solely in terms of the relative skills $c_{i, j}^{X}$. Because AHP only works with these ratios, the CobbDouglas utility function is hence fully compatible with the AHP approach.

Under the conditions (10)-(13) and (16), the compromise B would be selected 2379 times (using code similar to Figure 5).

(b) Perfect complements

Perfect complements are goods that are always consumed together in fixed proportions. For example, we buy a left and a right shoe. The indifference curves are L-shaped. The utility function describing perfect complement preferences is given by:

$$
u\left(x_{1}, x_{2}\right)=\min \left[a \cdot x_{1}, b \cdot x_{2}\right],
$$

where $a$ and $b$ are positive numbers that indicate the proportions in which the goods are consumed (eg, if $a=1$ and $b=2$, then one would consume two of good $x_{1}$ for every one of good $x_{2}$ ).
If the decision-maker has perfect-complement preferences (with $a=b$ ), then he would strictly prefer compromise candidate $\mathrm{B}$ over the other candidates if

$$
\begin{aligned}
& \min \left[s_{B}^{\text {eng }}, s_{B}^{\text {sales }}\right]>\max \left[\min \left[s_{A}^{\text {eng }}, s_{A}^{\text {sales }}\right],\right. \\
& \left.\quad \min \left[s_{C}^{\text {eng }}, s_{C}^{\text {sales }}\right]\right] .
\end{aligned}
$$

Condition (18) can be easily separated into two conditions, one for each alternative:

$$
\begin{aligned}
& \min \left[s_{B}^{\text {eng }}, s_{B}^{\text {sales }}\right]>\min \left[s_{A}^{\text {eng }}, s_{A}^{\text {sales }}\right] \text { and } \\
& \min \left[s_{B}^{\text {eng }}, s_{B}^{\text {sales }}\right]>\min \left[s_{C}^{\text {eng }}, s_{C}^{\text {sales }}\right] .
\end{aligned}
$$

Because of condition (9), condition (19) is weaker than conditions (7) and (8). We therefore use solely the (10)-(13) and the consistency $(\mathrm{CR}<0.1)$ conditions as requirement for the selection of candidate $\mathrm{B}$ (Figure 5). With the perfect complements condition, the candidate $\mathrm{B}$ is preferred in all possible 12650 scenarios.

(c) Perfect substitutes

As both skills have the same importance, indifference curves of two perfect substitutes goods are all parallel straight lines with slope of -1 . Candidate B is preferred if and only if

$$
s_{B}^{\text {sales }}+s_{B}^{\text {eng }}>\max \left[s_{A}^{\text {sales }}+s_{A}^{\text {eng }}, s_{C}^{\text {sales }}+s_{C}^{\text {eng }}\right] .
$$

Using condition (7)-(9) we can express this condition as

$$
c_{A B}^{\text {sales }}+c_{A B}^{\text {eng }}<2 \text { and } c_{C B}^{\text {sales }}+c_{C B}^{\text {eng }}<2 .
$$

With the conditions (10)-(13), (21), the consistency condition and the inverse mapping function $z(x)=(A-$ $1+x) / A$ for $(x>1)$ and $A /(A-1+(1 / x))$ for $x<1$ (where $A=2,3,4, \ldots$ ), $B$ is selected in 225 cases for $A=2,484$ cases for $A=3$ and 729 cases for $A=4$ (see Figure 6 for the pseudocode).

(d) Geometric mean

While the geometric mean does not have a direct relationship to a utility function, it has a nice intuitive property as a compromise level. In the problem of Table 4, if the advantage of candidate $\mathrm{A}$ over $\mathrm{B}$ in engineering is small compared to that of $\mathrm{B}$ over $\mathrm{C}$ is, we can write the inequality:

$$
c_{A, B}^{\text {eng }}<c_{B, C}^{\text {eng }} .
$$

If the corresponding statement holds with respect to sales skill (23), then B is a very attractive compromise candidate.

$$
c_{C, B}^{\text {sales }}<c_{B, A}^{\text {sales }} .
$$

In terms of absolute skills we get:

$$
\frac{s_{A}^{\text {eng }}}{s_{B}^{\text {eng }}}<\frac{s_{B}^{\text {eng }}}{s_{C}^{\text {eng }}}
$$

or

$$
s_{B}^{\text {eng }}>\sqrt{s_{A}^{\text {eng }} \cdot s_{C}^{\text {eng }}} \text {, where } s_{A}^{\text {eng }}>s_{C}^{\text {eng }} \text {. }
$$




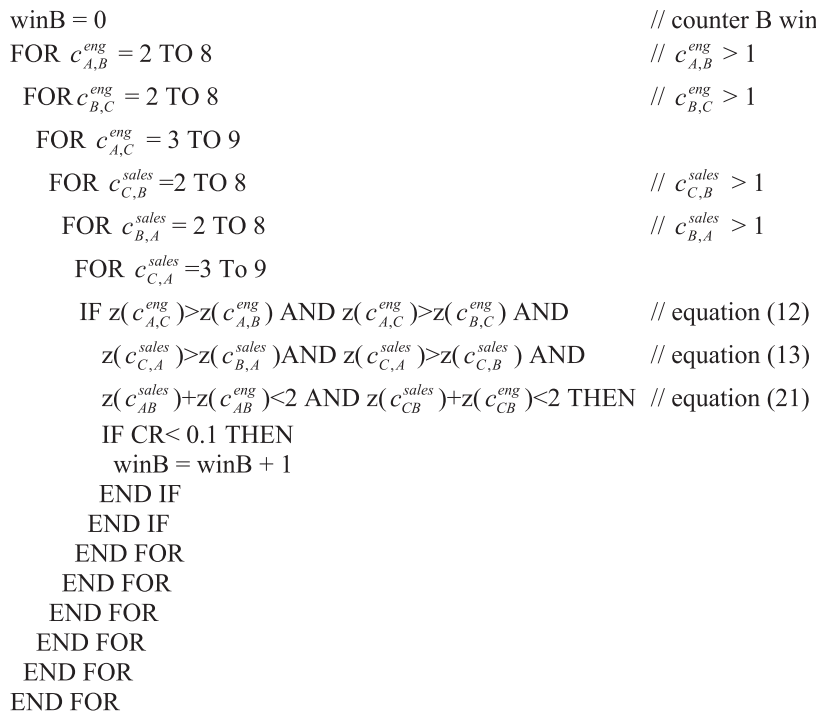

Figure 6 Pseudocode for the calculation of the maximum numbers of $\mathrm{B}$ wins.

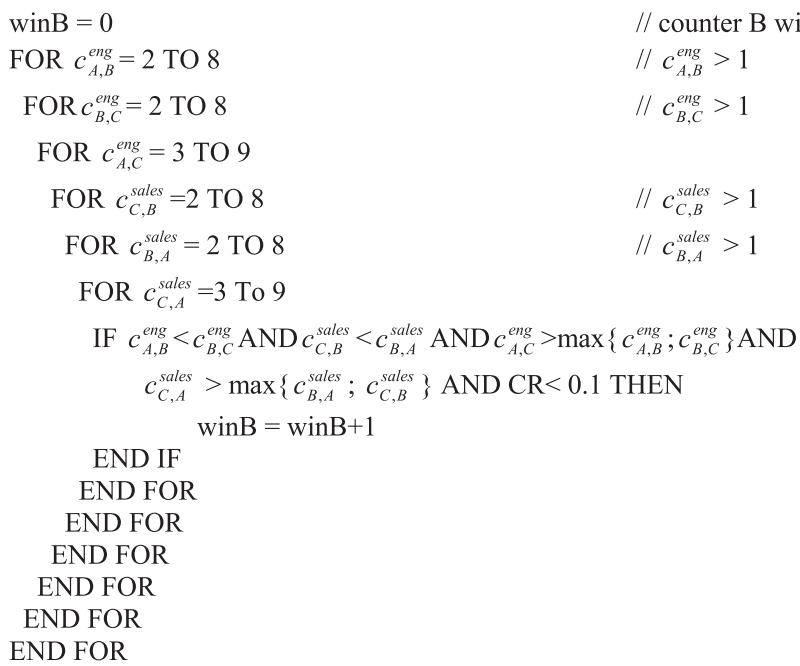

Figure 7 Pseudocode for the calculation of the number of times that $\mathrm{B}$ is selected with the geometric mean condition.

Similarly for the sales skill,

$$
s_{B}^{\text {sales }}>\sqrt{s_{A}^{\text {sales }} \cdot s_{C}^{\text {sales }}} \text {, where } s_{C}^{\text {sales }}>s_{A}^{\text {sales }} \text {. }
$$

Thus B's skill must be better than the geometric mean of the skills of the others. Note that for such comparisons we do not need the assumption of symmetry in (9).

With the conditions (10)-(13), (22), (23) and the consistency condition, B is selected in 2115 cases (see Figure 7 for the pseudocode).
Table 5 Parameters used with the different scales

\begin{tabular}{lc}
\hline Scale type & Parameters \\
\hline Linear & $a=1$ \\
Geometric & $a=2$ \\
Power & $a=2$ \\
Logarithmic & $a=2$ \\
Root square & $a=2$
\end{tabular}

\section{Decision with AHP and MAHP}

\subsection{Introduction}

In this section, we describe and discuss the hiring decision problem from Table 4 solved with AHP and MAHP. All the possible matrix combinations with an acceptable consistency are used with each preference scale. For the MAHP, four different weights normalisations are applied. Then, we compare the results of the AHP and MAHP with the consumer choice theory. The final position of the compromise candidate, $\mathrm{B}$, is our particular interest.

\subsection{Description}

All matrices modelling our problem (ie respecting conditions (10), (11), (12), (13) and CR <0.1) are considered with the seven measurement scales (Table 3 ) and the two different aggregation methods. Table 5 indicates the parameters used in our study.

The priorities are calculated with the normalised geometric mean, namely,

$$
l_{i}=\sqrt[n]{\prod_{j=1}^{n} c_{i, j}} / \sum_{j=1}^{n} l_{j},
$$

where $l_{i}$ is the priorityof the alternative $i, c_{i, j}$ is the comparison between $i$ and $j$ and $n$ is the dimension of the matrix.

This calculation provides similar results to the eigenvalue method for matrices of dimension three (Saaty and Vargas, 1984; Ishizaka, 2004b; Ishizaka and Lusti, 2006).

\subsection{Results}

We have seen with the standard consumer theory in Section 3.2 that we would expect that in many cases the consumer would prefer the compromise alternative B. The choice of a power or geometric scale excludes definitely (for AHP) or almost definitely (for MAHP) the compromise alternative (see Table 6). These scales are too extreme. With the other scales, the MAHP captures the obvious cases in which B should win (higher scores than the geometric mean and the CobbDouglas). However, it is still below the result of the perfect complements. The normalisation of the criteria weights has little impact on the final result. The selection of B with the traditional AHP is much more difficult.

Saaty's linear scale 1-9 gives few chances for the alternative B to be selected. Only 84 possibilities out of 12650 
Table 6 Number of combinations where the compromise alternative is selected under AHP

\begin{tabular}{|c|c|c|c|c|c|c|}
\hline \multirow{2}{*}{\multicolumn{2}{|c|}{ Scale type }} & \multicolumn{3}{|c|}{ Additive $A H P$} & \multicolumn{2}{|c|}{ Multiplicative AHP $\sum w_{j}=0.5$} \\
\hline & & \# of times $B$ wins & \multicolumn{2}{|c|}{$\%$ of times $B$ wins } & \# of times $B$ wins & $\%$ of times $B$ wins \\
\hline \multicolumn{2}{|l|}{ Geometric } & 0 & \multicolumn{2}{|c|}{0} & 1 & 0 \\
\hline \multicolumn{2}{|l|}{ Power } & 0 & 0 & \multicolumn{2}{|c|}{129} & 1 \\
\hline \multicolumn{2}{|l|}{ Linear $1-9$} & 84 & 1 & \multicolumn{2}{|c|}{4904} & 39 \\
\hline \multicolumn{2}{|l|}{ Logarithmic } & 444 & 4 & \multicolumn{2}{|c|}{6745} & 53 \\
\hline Root square & & 845 & 7 & \multicolumn{2}{|c|}{6197} & 49 \\
\hline \multicolumn{2}{|l|}{ Inverse linear } & 1179 & s & \multicolumn{2}{|c|}{4021} & 32 \\
\hline \multicolumn{2}{|l|}{ Balanced } & 1213 & \multirow{2}{*}{$2-$} & \multicolumn{2}{|c|}{5828} & 46 \\
\hline \multicolumn{2}{|c|}{ Perfect substitutes } & $225-729$ & & \multicolumn{2}{|c|}{$225-729$} & $2-6$ \\
\hline \multicolumn{2}{|c|}{ Geometric mean } & 2115 & & & 15 & 17 \\
\hline Cobb-Douglas & & 2379 & & & 79 & 19 \\
\hline Perfect comple & nts & 12650 & 10 & & & 100 \\
\hline Scale type & Multiplic & ative $A H P \sum w_{j}=1$ & Multiplic & $H P \sum w_{j}=2$ & Multiplic & $A H P \sum w_{j}=4$ \\
\hline & $\begin{array}{c}\text { \# of times } \\
B \text { wins }\end{array}$ & $\begin{array}{c}\% \text { of times } \\
B \text { wins }\end{array}$ & $\begin{array}{c}\text { \# of times } \\
B \text { wins }\end{array}$ & $\begin{array}{c}\% \text { of times } \\
B \text { wins }\end{array}$ & $\begin{array}{c}\text { \# of times } \\
B \text { wins }\end{array}$ & $\begin{array}{c}\text { \% of times } \\
B \text { wins }\end{array}$ \\
\hline Geometric & 0 & 0 & 0 & 0 & 0 & 0 \\
\hline Power & 130 & 1 & 128 & 1 & 128 & 1 \\
\hline Inverse linear & 4021 & 32 & 4040 & 32 & 4039 & 32 \\
\hline Linear 1-9 & 4918 & 39 & 4877 & 39 & 4908 & 39 \\
\hline Balanced & 5871 & 46 & 5888 & 47 & 5954 & 47 \\
\hline Root square & 6227 & 49 & 6242 & 49 & 6260 & 49 \\
\hline Logarithmic & 6750 & 53 & 6760 & 53 & 6772 & 54 \\
\hline
\end{tabular}

would yield $\mathrm{B}$, which appears to be an unreasonable result. Furthermore, in all the 84 cases, B yields a special configuration with the necessary but non-sufficient condition $\boldsymbol{C}_{A, B}^{\text {eng }}=\mathbf{2}$ and $C_{B, C}^{\text {sales }}=\mathbf{1} / \mathbf{2}$ (see Section 4.4).

The root square scale ( 845 selections for B), the balanced scale (1213) and the inverse linear scale (1179) offer more possibilities that the compromise alternative will be selected but still under the geometric mean and Cobb-Douglas criteria given by the consumer choice theory.

\subsection{Example of compromise selection with Saaty's scale}

The compromise will be selected only in a few cases with the linear scale 1-9 and under the non-sufficient condition that $\boldsymbol{C}_{A, B}^{\text {eng }}=\mathbf{2}$ and $\boldsymbol{C}_{B, C}^{\text {sales }}=\mathbf{1} / \mathbf{2}$. Figure 8 gives one example of them.

The global priorities are the average of the priorities across both skills:

$$
\begin{aligned}
& A=1 / 2 \cdot 0.606+1 / 2 \cdot 0.061=0.329 \\
& B=1 / 2 \cdot 0.333+1 / 2 \cdot 0.353=0.343(\text { winner }) \\
& C=1 / 2 \cdot 0.061+1 / 2 \cdot 0.585=0.328
\end{aligned}
$$

\subsection{Surprising example of compromise rejection with Saaty's scale}

AHP with Saaty's linear scale 1-9 prefers the extremes even if a compromise offers a better solution. We have three candidates:

- A is very good in sales but very poor in engineering

- $\mathrm{C}$ is very good in engineering but very poor in sales

- B is very good in sales but not as good as A and he is very good in engineering but not as good as C.

With the theory of consumer choice (see Section 3), the candidate B offers a clearly higher utility (under convex or linear preferences) and should be chosen.

One plausible representation in matrix comparisons could be given by Figure 9 .

The global priorities of this example are as follows:

1. A with 0.355

2. C with 0.355

3. B with 0.290

AHP does not classify the candidate B in first place but in last place! In order to verify the robustness of the results, a sensitivity analysis was performed (Figure 10). The compromise alternative B was never selected in this sensitivity analysis.

\section{Conclusion}

In this paper we have shown that the additive AHP will overrate alternatives with extreme ratings and penalise balanced ones. In some cases it may be mathematically impossible for 


\begin{tabular}{|c|c|c|c|c|}
\hline & $A$ & B & $C$ & priorities \\
\hline A & 1 & 2 & 9 & 0.606 \\
\hline$B$ & $1 / 2$ & 1 & 6 & 0.333 \\
\hline C & $1 / 9$ & $1 / 6$ & 1 & 0.061 \\
\hline
\end{tabular}

\begin{tabular}{|c|c|c|c|c|}
\hline 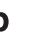 & $A$ & B & C & priorities \\
\hline$A$ & 1 & $1 / 7$ & $1 / 8$ & 0.061 \\
\hline B & 7 & 1 & $1 / 2$ & 0.353 \\
\hline C & 8 & 2 & 1 & 0.586 \\
\hline
\end{tabular}

Figure 8 Example where the compromise candidate $B$ is the best alternative $(A=0.329 ; B=0.343 ; C=0.328)$. The $C R$ are acceptable. (a) Matrix for the engineering skill $(\mathrm{CR}=0.01)$. (b) Matrix for sales skill $(\mathrm{CR}=0.03)$.

\begin{tabular}{|c|c|c|c|c|}
\hline & $A$ & B & C & priorities \\
\hline A & 1 & 3 & 9 & 0.655 \\
\hline B & $1 / 3$ & 1 & 7 & 0.290 \\
\hline C & $1 / 9$ & $1 / 8$ & 1 & 0.055 \\
\hline
\end{tabular}

\begin{tabular}{|c|c|c|c|c|}
\hline כ & $A$ & $\mathrm{~B}$ & C & priorities \\
\hline A & 1 & $1 / 7$ & $1 / 9$ & 0.055 \\
\hline B & 7 & 1 & $1 / 3$ & 0.290 \\
\hline C & 9 & 3 & 1 & 0.655 \\
\hline
\end{tabular}

Figure 9 Example where the compromise candidate B should be the best alternative but is the worst classified $(A=0.0 .355 ; \mathrm{B}=0.290$; $\mathrm{C}=0.355)$. The $\mathrm{CRs}$ are acceptable. (a) Matrix for the engineering skill $(\mathrm{CR}=0.08)$. (b) Matrix for sales skill $(\mathrm{CR}=0.08)$.

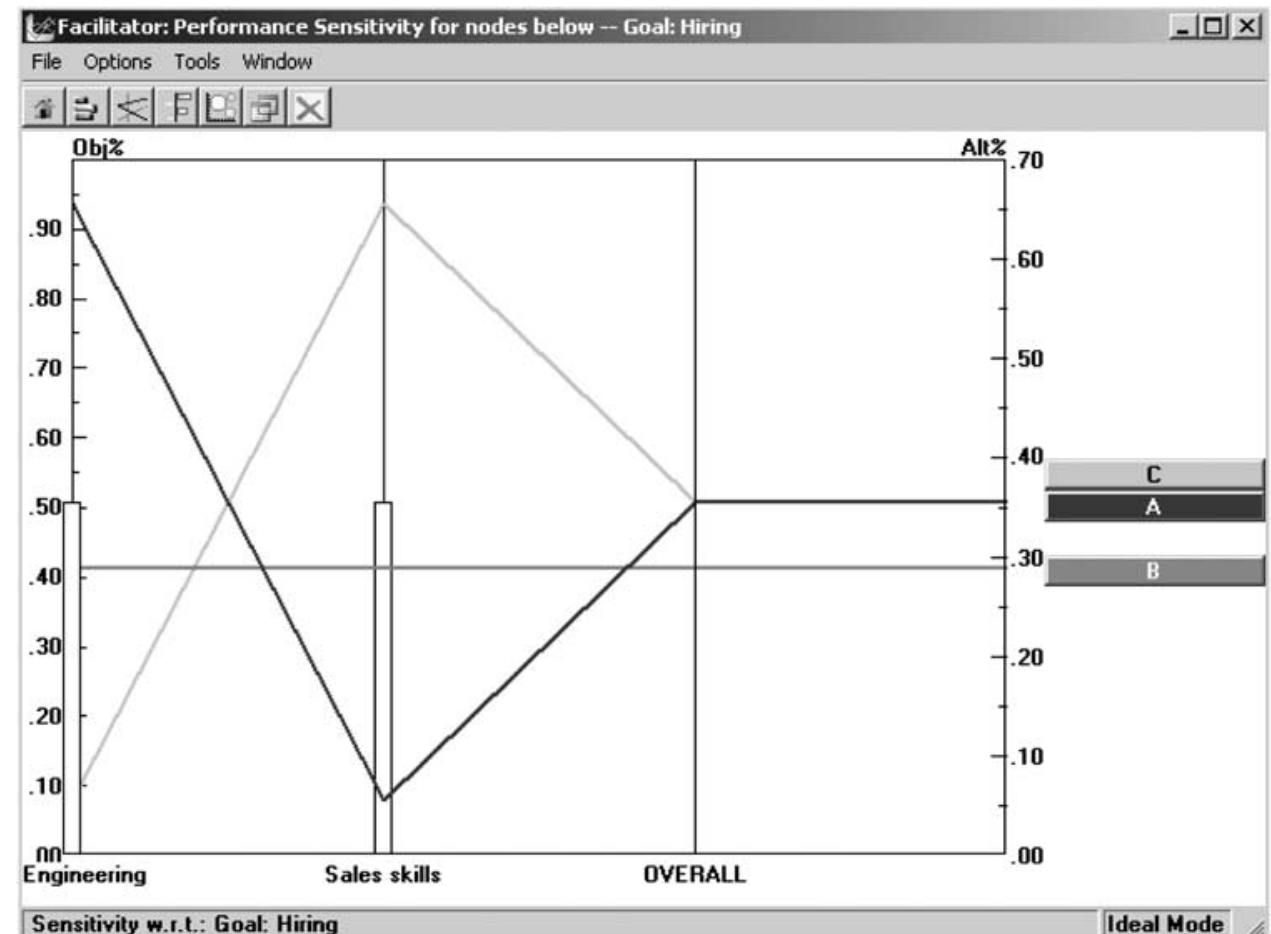

Figure 10 Sensitivity analysis.

Note: The left vertical axis represents the weight of the criteria and the right vertical axis gives the priority of each alternative. The candidate B is never selected: his line is never on top across any part of the graph.

AHP to select a compromise that achieves the highest overall ratings. This makes little sense from a practical point of view.

The impact of the preference scales is different with additive AHP from MAHP. Using additive AHP, the linear scale 1-9 offers very few possibilities for the compromise to be selected. These scales should be avoided unless we face a highly concave utility function.

The logarithmic scale, root square scale, inverse linear scale and balanced scale offer more possibilities for the compromise alternative to be selected, albeit they may ignore some superior compromises.
We do not suggest any fixed scale as a standard tool for AHP. This is because the interpretation of verbal expressions varies from one person to another; however, our observations confirm the work of Pöyhönen et al (1997), who do not support Saaty's scale and prefer a more harmonised scale such as the balanced scale or the inverse linear scale.

The MAHP, independently of the measurement scale (apart from the geometric scale and the power scale) and the normalisation of the weights criteria, ensures due consideration to the compromise alternative when compared with alternatives extremely attractive with respect to one 
criterion and extremely unattractive with respect to the other. This observation is particularly true for the new proposed logarithmic scale.

The examples presented here are typical of decision problems and must hence be taken very seriously. From the perspective of economists, decision making is almost always about making compromises. Trying to reach a better outcome in one dimension is often at the expense of achieving a worse outcome in another dimension. For instance, the production cost of a firm can often only be lowered at the expense of producing lower quality output. It is obvious to most consumers that if one chooses a lower-priced product (superior in the price dimension), it is usually at a lower quality (the other dimension): one gets what one pays for. A good decision-maker will typically have to correctly trade off one dimension against another. If a decision aid like the additive AHP tends to recommend extremes, which are good in only one respect, it will fail in its purpose. Thus, in addition to its property of rank reversal preservation, there appears to be another important advantage to using the MAHP.

\section{References}

Ahn BS and Choi SH (2008). ERP system selection using a simulationbased AHP approach: A case of Korean home shopping company. J Opl Res Soc 59(3): 322-330.

Akarte MM, Surendra NV, Ravi B and Rangaraj N (2001). Web based casting supplier evaluation using analytical hierarchy process. $J$ Opl Res Soc 52: 511-522.

Bañuelas R and Antony J (2007). Application of stochastic analytic hierarchy process within a domestic appliance manufacturer. $J \mathrm{Opl}$ Res Soc 58(1): 29-38.

Barzilai J (1997). Deriving weights from pairwise comparison matrices. J Opl Res Soc 48(12): 1226-1232.

Barzilai J and Golany B (1994). AHP rank reversal, normalization and aggregation rules. Inf Sys and Opl Res 32(2): 57-64.

Belton V and Gear T (1983). On a short-coming of Saaty's method of analytic hierarchies. Omega 11: 228-230.

Dyer JS (1990). Remarks on the analytic hierarchy process. Mngt Sci 36(3): 249-258.

Forman EH and Gass SI (2001). The analytic hierarchy process-An exposition. Opns Res 49(4): 469-486.

Fukuyama H and Weber WL (2002). Evaluating public school district performance via DEA gain functions. J Opl Res Soc 53(9): 992-1003.

Golden BL, Wasil EA and Harker PT (1989). The Analytic Hierarchy Process: Applications and Studies. Springer-Verlag: Heidelberg.

Harker PT and Vargas LG (1987). The theory of ratio scale estimation: Saaty's analytic hierarchy process. Mngt Sci 33(11): 1383-1403.

Harker PT and Vargas LG (1990). Reply to 'Remarks on the Analytic Hierarchy Process'. Mngt Sci 36(3): 269-273.

Ho W (2008). Integrated analytic hierarchy process and its applications-A literature review. Eur J Opl Res 186(1): 211-228.

Holder RD (1990). Some comment on the analytic hierarchy process. J Opl Res Soc 41(11): 1073-1076.

Holder RD (1991). Response to Holder's comments on the analytic hierarchy process: Response to the response. J Opl Res Soc 42(10): 914-918.

Ishizaka A (2004a). The advantages of clusters and pivots in AHP Proceeding 15th Mini-Euro Conference MUDSM (CD-Rom) ISBN 972-9044-52-X
Ishizaka A (2004b). Développement d'un système tutorial intelligent pour dériver des priorités dans l'AHP. $\mathrm{PhD}$ Thesis, University of Basle. Dissertation.de: Berlin.

Ishizaka A and Lusti M (2006). How to derive priorities in AHP: A comparative study. Cent Eur J Opns Res 14(4): 387-400.

Lee CW and Kwak NK (1999). Information resource planning for a health-care system using an AHP-based goal programming method. J Opl Res Soc 50(12): 1191-1198.

Leskinen P and Kangas J (2005). Rank reversals in multi-criteria decision analysis with statistical modelling of ratio-scale pairwise comparisons. J Opl Res Soc 56(12): 855-861.

Leung LC, Lam KC and Cao D (2006). Implementing the balanced scorecard using the analytic hierarchy process \& the analytic network process. J Opl Res Soc 57(6): 682-691.

Li X, Beullens P, Jones D and Tamiz M (2009). An integrated queuing and multi-objective bed allocation model with application to a hospital in China. J Opl Res Soc 60: 330-338.

Liberatore MJ and Nydick RL (2008). The analytic hierarchy process in medical and health care decision making: A literature review. Eur J Opl Res 189(1): 194-207.

Lootsma FA (1989). Conflict resolution via pairwise comparison of concessions. Eur J Opl Res 40(1): 109-116.

Lootsma FA, Mensch TCA and Vos FA (1990). Multi-criteria analysis and budget reallocation in long-term research planning. Eur J Opl Res 47(3): 293-305.

Lootsma FA (1993). Scale sensitivity in the multiplicative AHP and SMART. J Multi-criteria Decis Anal 2(2): 87-110.

Ma D and Zheng X (1991). 9/9-9/1 Scale method of AHP. 2nd Proceeding Int. Symposium on AHP, Vol. 1, University of Pittsburgh; Pittsburgh, PA, pp 197-202.

Mingers J, Liu W and Weng W (2009). Using SSM to structure the identification of inputs and outputs in DEA. J Opl Res Soc 60: 168-179.

Pöyhönen MA, Hämäläinen RP and Salo AA (1997). An experiment on the numerical modelling of verbal ratio statements. $J$ Multicriteria Decis Anal 6(1): 1-10.

Saaty TL (1977). A scaling method for priorities in hierarchical structures. J Math Psychol 15(3): 234-281.

Saaty TL (1980). The Analytic Hierarchy Process. McGraw-Hill: New York.

Saaty TL (1990). An exposition of the AHP in reply to the paper 'Remarks on the Analytic Hierarchy Process'. Mngt Sci 36(3): 259-268.

Saaty TL (1991). Response to Holder's comments on the analytic hierarchy process. J Opl Res Soc 42(10): 909-929.

Saaty TL and Vargas LG (1984). Comparison of eigenvalue, logarithmic least squares and least squares methods in estimating ratios. Math Modelling 5(5): 309-324.

Salo AA and Hämäläinen RP (1997). On the measurement of preferences in the analytic hierarchy process. J Multi-criteria Decis Anal 6(6): 309-319.

Sha DY and Che ZH (2006). Supply chain network design: Partner selection and production/distribution planning using a systematic model. J Opl Res Soc 57(1): 52-62.

Stam A and Duarte Silva P (2003). On multiplicative priority rating methods for AHP. Eur J Opl Res 145(1): 92-108.

Tavana M (2006). A priority assessment multi-criteria decision model for human spaceflight mission planning at NASA. J Opl Res Soc 57(10): 1197-1215.

Triantaphyllou E (2001). Two new cases of rank reversals when the AHP and some of its additive variants are used that do not occur with the multiplicative AHP. J Multi-criteria Decis Anal 10(1): $11-25$.

Triantaphyllou E and Baig K (2005). The impact of aggregating benefit and cost criteria in four MCDA methods. IEEE T Eng Mngt 52(2): 213-226. 
Vaidya O and Kumar S (2006). Analytic hierarchy process: An overview of applications. Eur J Opl Res 169(1): 1-29.

Vargas LG (1990). An overview of the analytic

Vargas LG (1990). An overview of the analytic hierarchy process and its applications. Eur J Opl Res 48(1): 2-8.

Vargas LG (1997). Comments on Barzilai and Lootsma: Why the multiplicative AHP is invalid: A practical counterexample. J Multicriteria Decis Anal 6(4): 169-170.

Wheeler S (2006). An analysis of combined arms teaming for the Australian defence force. J Opl Res Soc 57(11): 1279-1288.

Winkler R (1990). Decision modeling and rational choice: AHP and utility theory. Mngt Sci 36(3): 247-248.
Yeo G-T, Song D-W, Dinwoodie J, Roe M (2009). Weighting the competitiveness factors for container ports under conflicting interests. $J \mathrm{Opl}$ Res Soc, advance online publication, doi: 10.1057/jors.2009.88.

Zahedi F (1986). The analytic hierarchy process: A survey of the method and its applications. Interface 16(4): 96-108.

Received August 2008; accepted January 2010 after one revision 